\title{
Alberto GIL NOVALES, Diccionario biográfico de España (1808-1833). De los orígenes del liberalismo a la reacción absolutista
}

\section{Lluís Roura}

\section{(2) OpenEdition}

Édition électronique

URL : https://journals.openedition.org/ahrf/12367

DOI : 10.4000/ahrf.12367

ISSN : 1952-403X

Éditeur :

Armand Colin, Société des études robespierristes

Édition imprimée

Date de publication : 1 juin 2012

Pagination : 212-215

ISBN : 978-2-7489-0161-0

ISSN : 0003-4436

Référence électronique

Lluís Roura, «Alberto giL novales, Diccionario biográfico de España (1808-1833). De los orígenes del liberalismo a la reacción absolutista ", Annales historiques de la Révolution française [En ligne], 368 | avriljuin 2012, mis en ligne le 24 septembre 2012, consulté le 24 avril 2022. URL : http:// journals.openedition.org/ahrf/12367 ; DOI : https://doi.org/10.4000/ahrf.12367

Ce document a été généré automatiquement le 24 avril 2022.

Tous droits réservés 


\title{
Alberto GIL NOVALES, Diccionario biográfico de España (1808-1833). De los orígenes del liberalismo a la reacción absolutista
}

\author{
Lluís Roura
}

\section{RÉFÉRENCE}

Alberto GIL NOVALES, Diccionario biográfico de España (1808-1833). De los orígenes del

liberalismo a la reacción absolutista, 3 vol. , Madrid, Fondation Mapfre, 2010, 3406 p., ISBN : 978-8-49844-208-3, $120 €$.

1 Depuis la publication de ses premières études, ainsi qu'au fil de toute sa trajectoire intellectuelle, Alberto Gil Novales a toujours montré un intérêt particulier pour la récupération de l'identité des protagonistes de l'histoire politique espagnole des XVIII ${ }^{\mathrm{e}}$ et $\mathrm{XIX}^{\mathrm{e}}$ siècles. Le manque d'outils essentiels pour l'historien, comme un dictionnaire biographique d'Espagne, le mena dès le début à rassembler des figures importantes de cette période, qu'une historiographie favorable à l'autoritarisme politique du pays laissait de côté. C'était déjà le cas des biographies tracées dans l'ouvrage Las pequeñas atlántidas (Barcelone, 1959), magnifique anticipation de ce que nous offre l'œuvre de son auteur et une référence de ce que l'on a appelé « le réveil de la conscience critique sous le franquisme ».

2 La vaste prosopographie qu'Alberto Gil Novales incorpora, des années plus tard, comme une sorte d'appendice à Las Sociedades Patrióticas (1820-1823) (Madrid, 1975), était déjà clairement précurseur de ce qui allait être une constante dans son travail intellectuel : le souci de ne pas négliger les détails, pour infimes qu'ils soient, qui apparaîtraient au passage et la volonté tenace de les mettre immédiatement à la portée de la communauté scientifique. Cette attitude le mena à concevoir l'élaboration d'un 
dictionnaire biographique des origines du libéralisme, qui allait être en permanente construction car la biographie des personnages n'était pas envisagée comme une fin en soi sinon comme une voie permettant d'approcher la connaissance historique. De telle manière que la publication du Diccionario biográfico del Trienio Liberal (Madrid, 1991), du Diccionario biográfico español, 1808-1833 (Personajes Extremeños) (Mérida, 1998) et du Diccionario biográfico aragonés, 1808-1833 (Huesca, 2005) ne fut pas une simple anticipation d'un travail qui devait culminer dans les trois volumes de l'œuvre dont nous faisons ici le compte rendu; ce fut plutôt un reflet de l'état des connaissances à un moment donné, en même temps que l'apparition d'inappréciables instruments pour le progrès de la connaissance historique d'un moment-clé de notre histoire. Et c'est aussi le caractère qu'a globalement le Diccionario biográfico de España (1808-1833). De los orígenes del liberalismo a la reacción absolutista. Il s'agit d'une œuvre colossale, mais qui n'en est pas moins une photographie instantanée de la connaissance, à la fois vaste et profonde, que son auteur a atteinte à un moment déterminé de son incessante activité scientifique sur la révolution libérale espagnole ; connaissance aujourd'hui d'une pleine maturité intellectuelle. C'est pour cela qu'Alberto Gil Novales sait, à tout moment, qu'un dictionnaire biographique doit toujours être ouvert à de constantes ampliations et révisions des données et des nuances, ce qui se reflète non seulement dans le style de ses biographies, ou dans la permanente correction des contenus et des références, mais aussi dans les contributions successives que l'auteur matérialise dans ses communications et ses publications.

3 En dépit de ces dimensions, on ne trouvera pas dans le Diccionario... de concessions à la frivolité ni au hasard, bien que son auteur ne renonce dans sa rédaction ni aux annotations critiques ni aux clins d'œil et aux complicités avec ses lecteurs. Le soin intellectuel se reflète bien dans le titre même du dictionnaire. Il s'agit, comme son auteur l'indique, d'un dictionnaire biographique " d'Espagne » et non d'un dictionnaire biographique "espagnol». Il esquive ainsi l'a priori nationaliste dans lequel s'est en partie embourbé le polémique Diccionario biográfico español que publie la Real Academia Española de la Historia; et il établit, de surcroît, un cadre qui permet d'accueillir, à juste titre, la biographie de ces personnages étrangers qui vécurent en Espagne, entre 1808 et 1833, ou qui eurent sur elle une influence directe. Par ailleurs, il facilite en même temps la prise en compte des événements, des concepts et des penseurs qui eurent un écho et une influence sur les Espagnols qui vécurent au cours de cette période. Comme le signale son auteur dans l'introduction, ce critère a aussi été appliqué aux personnages qui intervinrent dans le mouvement américain, c'est-à-dire que ne sont inclus dans cet ouvrage que les individus hispano-américains qui vécurent en Espagne, à un moment ou à un autre entre 1808 et 1833, ou eurent sur elle une influence directe, ce qui dans ce cas - comme il le reconnaît lui-même - ne cesse pas d'être une restriction regrettable bien qu'obligée par les nécessaires limites physiques et matérielles de l'œuvre qui était menée à terme.

Le sous-titre du dictionnaire, De los orígenes del liberalismo a la reacción absolutista, nous situe face à un ouvrage dont l'auteur lui-même considère qu'il va bien au-delà d'une compilation de biographies et qui peut être considéré, sans le moindre doute, comme une large voie d'accès multiple à l'information et à la compréhension historique des origines du libéralisme en Espagne et des résistances opposées par la réaction absolutiste; ce qui est mené à terme au travers de la biographie de protagonistes de 
tout type et de toute catégorie. Il n'y a pas d'autre limitation que celle qu'impose l'état des connaissances actuelles sur l'époque.

5 Les plus de vingt-cinq mille biographies que contient le Diccionario... sont pratiquement dans leur totalité l'œuvre d'Alberto Gil Novales. L'exception concerne un peu plus d'une vingtaine d'auteurs qui rédigèrent, en leur temps, une petite partie des articles du Diccionario biográfico del Trienio Liberal, dont le contenu a été incorporé dans sa totalité à cet ouvrage, après avoir été révisé et augmenté par Alberto Gil Novales lui-même. Chacune des entrées répond au critère de présentation adopté par son auteur : nom et prénom du personnage, titre nobiliaire le cas échéant, lieux et dates de naissance et de décès, synthèse biographique et, finalement, les références bibliographiques et documentaires sur lesquelles s'est basé l'auteur. Grâce à cette structure, il a obtenu une sorte de kaléidoscope de personnages qui reflètent un nombre interminable d'activités économiques, administratives, professionnelles, diplomatiques, scientifiques, etc. ainsi que de tout type de rangs sociaux et institutionnels - militaires, ecclésiastiques, professionnels, etc. Bien qu'inévitablement peu importants en nombre, les personnages féminins sont aussi présents, répondant à la volonté manifestée dans ce sens par l'auteur dans la présentation de l'œuvre.

6 La longueur de chaque article est variable en fonction soit de l'information dont on dispose et de la notoriété du personnage soit de la volonté de récupération d'individus perdus dans l'oubli ou relégués au second plan - comme cela pourrait être le cas des biographies de Juan Calderón ou de Miguel Ricardo de Álava. Toutefois, l'auteur n'économise pas non plus les renseignements relatifs à des citoyens « ordinaires » comme dans le cas des sœurs Toledo et Cebolleda qui furent jugées en 1811 pour violation de la confiance et de la foi due à quelqu'un, conjointement à neuf autres femmes de Molina de Aragón, par un juge qui n'avait pour unique but que de les voler... de telle manière que nombre des personnages biographiés nous rappellent que l'histoire est pour l'essentiel beaucoup plus que l'œuvre des "grands hommes». Les articles les plus notoires occupent une place minimum de trois à quatre colonnes et un maximum de neuf, avec quelques exceptions, comme celle qui concerne Espoz y Mína, à qui sont consacrées treize colonnes, ou celle de Juan Lorenzo Calvo de Rozas, avec quatorze. Toutefois, logiquement, la plupart n'occupent que quelques lignes. Il faut aussi signaler que l'incorporation du contenu du Diccionario biográfico del Trienio Liberal a permis de maintenir l'intérêt de certains articles rédigés par ceux qui avaient mené à terme de grandes recherches sur le personnage biographié - comme, par exemple, l'article sur J. A. Llorente écrit par Gérard Dufour, celui de Miñano rédigé par Claude Morange ou celui de Gallardo réalisé par Alejandro Pérez Vidal. Par ailleurs, il ne serait pas juste de passer sous silence la méticulosité avec laquelle ont été menées à terme l'approche ainsi que l'identification, dans tous les cas où cela a été possible, des auteurs qui signaient d'un pseudonyme, ou de leurs initiales. Le Diccionario... est désormais indispensable pour déconstruire des erreurs et des confusions découlant de l'énorme homonymie de l'histoire espagnole ; il suffit de mentionner, à cet égard, l'existence de cent cinquante entrées (!) de personnages dont le patronyme est Álvarez.

7 L'intérêt du Diccionario est incalculable : comme ouvrage de référence, comme outil de travail, comme grande synthèse dans l'étude de toute une époque. Sans le moindre doute, son caractère interdisciplinaire en fait une œuvre d'une grande utilité autant pour les spécialistes de l'histoire que ceux de la littérature, de l'art, des idées, de la politique, de la science, etc. Son importance comme ouvrage de référence est en outre 
décuplée par la multifonctionnalité que donne à l'édition imprimée l'accompagnement d'un inestimable DVD comportant tout le contenu du dictionnaire, de telle manière que le lecteur pourra mener à terme tout type de recherche : par nom, par titre, par date, par mot, etc., ce qui fait de ce Diccionario... une source inépuisable de possibles sondages pour stimuler en même temps et de manière continue de nouvelles recherches.

Conscient de ce que dans un dictionnaire tel que celui-ci ne peut entrer que ce que l'historiographie a apporté, l'auteur indique - en plus de ses recherches propres - les sources et les références bibliographiques qui soutiennent chacune de ses biographies. Parmi celles-ci se trouvent de la documentation paroissiale, des guides destinés aux étrangers, des documents du fisc, des états ecclésiastiques, commerciaux et militaires, des articles de presse, des actes de sociétés, des correspondances, etc. Les références apportées, en plus d'accréditer l'objectivité du travail scientifique effectué, offrent au lecteur des pistes précieuses pour qui souhaite élargir ses connaissances et ses recherches. La centaine de pages de la bibliographie générale qui figure à la fin du troisième volume - avec plus de deux mille trois cents références -, les plus de trois cent cinquante périodiques consultés dont l'auteur donne aussi la liste dans le dernier volume, ainsi que le vaste inventaire de documentation inédite consultée dans plus de quarante archives - nationales et étrangères - et la centaine de catalogues de librairies anciennes qui ont été utilisés donnent une idée de la monumentalité du travail effectué par l'auteur ; travail incroyable pour avoir été mené à terme pratiquement par un seul homme bien que, comme on peut le voir dans les remerciements, celui-ci ait pu compter sur un nombre considérable d'autres personnes qui, d'une manière ou d'une autre, lui ont apporté leur soutien ou leur aide.

Alberto Gil Novales dit dans l'introduction du Diccionario... qu'il prétend « refléter les vies, les idées, les vicissitudes et les aspirations de nos compatriotes de ces années-là ainsi que des non Espagnols qui étaient en contact immédiat avec eux » (p. 15). Mission très largement remplie car, et ce n'est pas la moindre chose, l'ouvrage nous offre beaucoup plus: un témoignage irréfutable de la continuité de l'histoire d'Espagne comprise entre les années 1775 et 1845 . Une continuité marquée par l'influence des Lumières, par le lien entre celles-ci et le libéralisme, par l'impact de la Révolution française, par la dimension révolutionnaire du processus enclenché à partir de 1810, et par la poussée du Triennat libéral mais aussi par la transcendance des résistances absolutistes. La complexité de ces faits donne sens aux comportements des personnages qui furent nombreux, avec une grande variabilité de leurs conduites - comme on peut l'observer dans leurs biographies -, à glisser progressivement de leurs aspirations révolutionnaires d'origine vers des attitudes plus conformistes et modérées...

Face à des conclusions simples ou précipitées de l'histoire, le Diccionario... d'Alberto Gil Novales nous rappelle que pour la compréhension de toute période historique, comme dans ce cas celle des origines du libéralisme, on ne peut pas se passer de l'historicité de ses protagonistes. 